\title{
Beneficial Bacteria Identified for the Control of Botrytis cinerea in Petunia Greenhouse Production
}

\author{
Kaylee A. South, ${ }^{1}$ Francesca Peduto Hand, ${ }^{2}$ and Michelle L. Jones ${ }^{1, \dagger}$ \\ ${ }^{1}$ Department of Horticulture and Crop Science, The Ohio State University, Wooster, OH 44691 \\ ${ }^{2}$ Department of Plant Pathology, The Ohio State University, Columbus, OH 43210
}

\begin{abstract}
Botrytis cinerea infects most major greenhouse crops worldwide. With its increasing resistance to conventional fungicides and the movement of the greenhouse industry toward more sustainable production practices, alternative methods of control are needed. The objective of this study was to evaluate a collection of 60 bacterial strains through both a dual-culture assay and greenhouse trials to identify strains with biocontrol activity against $B$. cinerea. For the dual-culture assay, each bacterial strain was streaked on potato dextrose agar medium with $B$. cinerea. The $B$. cinerea growth reduction and the zone of inhibition were measured. Thirty-five strains reduced the growth of $B$. cinerea. All strains were also tested in an initial greenhouse trial in which Petu-

severity indices calculated from the daily flower gray mold severity ratings of all tagged flowers were used to identify the seven topperforming strains. These seven strains were then evaluated in a greenhouse validation trial. The methods were similar to those of the initial greenhouse trials except that replicate numbers were increased. Three strains (Pseudomonas protegens AP54, Pseudomonas chlororaphis 14B11, and Pseudomonas fluorescens 89F1) were selected for the ability to reduce $B$. cinerea infection in a greenhouse production setting. These strains can be used in future studies to develop additional biocontrol products for the management of $B$. cinerea in floriculture crops.
\end{abstract} nia $\times$ hybrida 'Carpet Red Bright' was sprayed and drenched with the bacteria biweekly for 6 weeks. All open flowers were tagged, and plants were inoculated with $B$. cinerea $\left(1 \times 10^{4}\right.$ conidia per $\left.1 \mathrm{ml}\right)$. Disease
Keywords: bacteria, biocontrol, botrytis blight, floriculture, fungus, gray mold, Pseudomonas
Botrytis cinerea, the causal agent of gray mold, is one of the most common and economically devastating pathogens of greenhouse crops because of its wide host range and ability to infect plants at all stages of the production chain (Dean et al. 2012; Dik and Wubben 2007). The production of flowering bedding plants is particularly problematic because of the high susceptibility of the flowers to gray mold. Infected flowers reduce crop quality, and in severe cases, they can lead to crop loss (Dik and Wubben 2007). The greenhouse environment in early spring can provide ideal conditions for $B$. cinerea to infect plants. Cool temperatures, high humidity, reduced air movement, and wet flowers and leaves are conducive to B. cinerea infection (Dik and Wubben 2007).

Increasing air temperatures and ventilation and decreasing relative humidity can be effective ways to reduce $B$. cinerea infection, but these environmental manipulations may not be feasible for some greenhouse production facilities (Dik and Wubben 2007). Fungicides are commonly used to manage this pathogen, but resistance to several active ingredients has been reported in various geographical regions (Fungicide Resistance Action Committee 2018) for field crops (Cosseboom et al. 2019) and greenhouse crops (Muñoz et al. 2019). The emergence of resistance to chemical fungicides coupled

${ }^{\dagger}$ Corresponding author: M. L. Jones; jones.1968@ osu.edu

Funding: Salaries and research support were provided in part by state and federal funds appropriated to the OARDC, The Ohio State University. Journal Article Number HCS 19-16. This work was financially supported by the American Floral Endowment and The Ohio State University DC Kiplinger Endowment. Support was also provided by The Ohio State University Deans Distinguished Fellowship.

*The $\boldsymbol{e}$-Xtra logo stands for "electronic extra" and indicates that one supplementary table is published online.

The author(s) declare no conflict of interest.

Accepted for publication 7 January 2020.

(c) 2020 The American Phytopathological Society with increased customer demands for plants free of pesticide residues have created a need for additional management options (Lamichhane et al. 2016; Pal and McSpadden Gardener 2006; Xia et al. 2006).

Biological control or biocontrol of plant pathogens is an alternative method of management that uses organisms that are introduced or already established in a system (Pal and McSpadden Gardener 2006). Beneficial plant-microbe interactions have been used throughout history for controlling diseases in trees, row crops, and greenhouse crops caused by both soilborne and foliar pathogens (Cook and Baker 1983; Fravel 2005). The greenhouse offers a unique opportunity to study and implement biocontrol of plant pathogens owing to the level of environmental control and the type of crops grown (Paulitz and Bélanger 2001). There is an increasing interest in understanding how biocontrol can be used as an additional tool in integrated pest management programs for many pathogens (Pal and McSpadden Gardener 2006; Syed Ab Rahman et al. 2018), including B. cinerea (Elad and Steward 2007). As a result, biopesticides are currently the fastest-growing sector of the crop protection market, and microbial biopesticides represent the largest use segment of the biopesticide industry (Meister Media Worldwide 2014).

Studies have shown that bacteria have the potential to control B. cinerea in crops, such as grapevine (Barka et al. 2002), tomato (Yildiz et al. 2007), and petunia (Gould et al. 1996). Promising bacterial strains are typically identified by isolation from either a different plant system (e.g., an isolate from onion root evaluated in grapevine) (Barka et al. 2002) or the same plant system (e.g., isolates from tomato leaves evaluated in tomato plants) (Yildiz et al. 2007). Research on the biocontrol of gray mold has been conducted with greenhouse floriculture crops. A yeast and a bacterium isolated from rosebuds were found to reduce lesions caused by $B$. cinerea on whole cut roses by 63 and $48 \%$, respectively, whereas iprodione-treated roses had a $74 \%$ reduction in lesions (Redmond et al. 1987). A Pseudomonas fluorescens strain that reduced the incidence of gray mold was identified from a collection of 172 bacterial strains isolated from petunia tissues. When applied to petunia flowers on plants in an incubation chamber, disease incidence was reduced by an average of $77 \%$ (Gould et al. 1996).

Studies evaluating large bacteria collections to identify potential biocontrol agents commonly use an in vitro method to narrow down 
the candidates before in planta studies are conducted. In vitro screening efforts can provide valuable information, such as an indication of mode of action, but they seldom accurately predict what is observed in in planta studies. The complex interactions between the introduced microbe, plant, environment, and pathogen can be most accurately evaluated using in planta studies (Köhl et al. 2019; Pal and McSpadden Gardener 2006). Milus and Rothrock (1997) identified top-performing strains in an in vitro assay looking at inhibition zone width for the potential control of Pythium spp., but these strains were not as effective as others in the field. In light of these and other similar results, it is becoming more common to evaluate potential beneficial microbes in the system for which they are being studied (Fravel 2005).

The overall goal of this study was to identify bacteria from a collection of 60 bacterial strains for the potential to control the fungal pathogen $B$. cinerea in greenhouse bedding plant production. The specific objectives were (i) to identify bacterial strains that can reduce $B$. cinerea growth through a dual-culture assay and (ii) to identify bacterial strains that can reduce gray mold severity in planta using greenhouse trials.

\section{Materials and Methods}

Dual-culture assay. Forty-five bacterial strains from Dr. Christopher Taylor (The Ohio State University, Wooster, $\mathrm{OH}$ ) previously described by Subedi et al. (2019) along with 15 strains from Dr. Joseph Kloepper (Auburn University, Auburn, AL) were tested for the ability to inhibit the growth of $B$. cinerea in a dual-culture assay adapted from Wang et al. (2009) (Table 1). Bacterial strains were grown from $-80^{\circ} \mathrm{C}$ glycerol storage on $\mathrm{LB}$ agar for $24 \mathrm{~h}$ at $28^{\circ} \mathrm{C}$. Bacteria were resuspended in Luria-Bertani (LB) broth, measured for optical density (OD) at $595 \mathrm{~nm}$ on a spectrophotometer (DTX880; Beckman Coulter, Brea, CA), and adjusted to an $\mathrm{OD}_{595}$ of 0.2 . The $B$. cinerea isolate acquired from the Application Technology Research group (U.S. Department of Agriculture/Agricultural Research Service, Wooster, $\mathrm{OH}$ ) was originally isolated from annual begonias, and its identity was confirmed by PCR with a primer set specific to B. cinerea (Rigotti et al. 2002). For the dual-culture assay, a single bacterial strain and $B$. cinerea were cocultured on potato dextrose agar (PDA). A 5-mm-diameter cork borer was used to cut a mycelial plug from the edge of a 3-day-old B. cinerea culture on PDA. The plug was placed in the center of a 100-mm petri dish containing approximately $25 \mathrm{ml}$ of PDA (Fig. 1). On two opposite sides of the plug, $10 \mu \mathrm{l}$ of bacterial suspension was streaked in a straight line $2.5 \mathrm{~cm}$ away from the plug so that the bacterial streaks were parallel to each other (Fig. 1). Ten microliters of sterile LB broth were used as the negative control. For a positive control, three sterile 6-mm filter paper disks were placed in lines on each side of the plug $2.5 \mathrm{~cm}$ from the center, and $5 \mu \mathrm{l}$ of $58.6 \mathrm{mM}$ cycloheximide (water:ethanol, 1:1 vol/vol) was added to each disk. Petri dishes were sealed with parafilm and incubated at $20^{\circ} \mathrm{C}$ (I-35 VL; Percival Scientific Inc., Boone, IA). Each treatment was replicated three times and arranged in a randomized complete block design inside the incubator.

When the mycelial growth in the negative control treatment reached the edges of the petri dish, measurements were taken for all treatments. The growth of $B$. cinerea was measured from the edge of the agar plug to the leading edge of the mycelial growth parallel $(R 1)$ and perpendicular $(R 2)$ to the bacterial streak (Fig. 1). These measurements were taken for each of the bacterial streaks on the plate for a total of four growth measurements per petri dish. The average of $R 1$ and $R 2$ measurements were used to calculate the percentage growth reduction compared with the negative control according to the following formulas:

$$
\begin{aligned}
& R 1 \text { Growth Reduction }(\%)=\frac{\left(R 1_{\text {control }}-R 1_{\text {Dual Plate }}\right)}{\mathrm{R} 1_{\text {control }}} \times 100 \\
& R 2 \text { Growth Reduction }(\%)=\frac{\left(R 2_{\text {control }}-R 2_{\text {Dual Plate }}\right)}{R 2_{\text {control }}} \times 100
\end{aligned}
$$

A zone of inhibition, defined as the distance from the leading edge of bacteria growth to that of $B$. cinerea mycelium (R3), was also measured on each side of the plug (Fig. 1), and measurements were averaged for each plate.

Initial greenhouse trial for bacterial strain selection. Experimental design. The initial greenhouse trial was conducted using an augmented design (Federer and Raghavarao 1975). All 60 bacterial strains from the collection were split into three experimental groups and evaluated for their ability to control gray mold. A commercial biocontrol product containing Bacillus subtilis QST 713 (Cease; BioWorks, Victor, NY) served as the positive control, whereas the negative control was sterile LB medium. There were three replicates of each bacterial strain, and both the positive and negative controls were overreplicated, with 12 replicates in each experimental group.

Plant material. Petunia $\times$ hybrida 'Carpet Red Bright' seeds (Ivy Garth Seeds \& Plants, Chesterland, $\mathrm{OH}$ ) were sown in soilless substrate (Promix PGX; Premier Tech, Quebec, Canada) in plug trays and grown under fluorescent lighting for 4 weeks. Plugs were transplanted into 11.4-cm plastic pots into soilless substrate (Baccto Bark 1000 Professional Planting Mix; Michigan Peat Company, Houston, TX) and moved to the greenhouse. Day temperature was maintained between 21 and $24^{\circ} \mathrm{C}$, and night temperature was between 16 and $18^{\circ} \mathrm{C}$ with a 14 -h photoperiod. Light levels were maintained at 300 $\mathrm{W} / \mathrm{m}^{2}$ using supplemental lighting. Petunias were irrigated as needed with $50 \mathrm{mg}$ /liter of $\mathrm{N}$ from $15 \mathrm{~N}: 2.2 \mathrm{P}: 12.5 \mathrm{~K}: 2.9 \mathrm{Ca}: 1.2 \mathrm{Mg}$ watersoluble fertilizer (JR Peters, Allentown, PA).

Bacterial treatment of plants. All treatments were applied at transplant and every 2 weeks thereafter for a total of four applications. Bacterial treatments were prepared by growing strains on LB agar from glycerol storage for $36 \mathrm{~h}$ at $28^{\circ} \mathrm{C}$. Single colonies were selected and grown in LB broth for $9 \mathrm{~h}$ at $28^{\circ} \mathrm{C}$ on an orbital shaker at $200 \mathrm{rpm}$. Optical density was measured at $600 \mathrm{~nm}$ using a spectrophotometer (UV-1600PC; VWR International, LLC, Radnor, PA) and adjusted with sterile $\mathrm{LB}$ broth to an $\mathrm{OD}_{600}$ of 0.8 . Bacterial cultures were diluted 1:100 with reverse osmosis (RO) $\mathrm{H}_{2} \mathrm{O}$. The positive control (Cease; BioWorks) was applied at the recommended rate of $15 \mathrm{ml} / \mathrm{liter}$. At transplant, $80 \mathrm{ml}$ of each treatment was applied as a drench to each pot. For the second and third applications, $80 \mathrm{ml}$ of each treatment was sprayed using handheld plastic trigger spray bottles onto the leaves, flowers, and potting substrate. For the final application, treatments were applied as a spray $(40 \mathrm{ml})$ to the leaves and flowers and as a drench $(80 \mathrm{ml})$ to the potting substrate.

Pathogen inoculation. After the final treatment application, the plants were moved into a greenhouse environment more conducive for $B$. cinerea infection. Plants were placed under tents created by draping clear greenhouse plastic over PVC pipe structures on each of three greenhouse benches. Inside each tent, an automated fogging system (Trident Single Zone Controller Model T3A; Phytotronics, Inc., Earth City, MO) was used to increase humidity and maintain water droplets on the plants, fogging for approximately $8 \mathrm{~s}$ every $30 \mathrm{~min}$. The greenhouse settings were adjusted to a day temperature between 18.3 and $21.1^{\circ} \mathrm{C}$ and a night temperature between 15.6 and $18.3^{\circ} \mathrm{C}$ with reduced light levels, and the horizontal airflow fans were turned off. Plants were irrigated with $50 \mathrm{mg} / \mathrm{liter}$ of $\mathrm{N}$ from $15 \mathrm{~N}: 2.2 \mathrm{P}: 12.5 \mathrm{~K}: 2.9 \mathrm{Ca}: 1.2 \mathrm{Mg}$ water-soluble fertilizer (JR Peters) for $1 \mathrm{~min}$ twice a day through drip irrigation. Before $B$. cinerea inoculation, all open flowers on each plant were tagged for identification and subsequent rating. B. cinerea was grown on PDA at $20^{\circ} \mathrm{C}$ in darkness for at least 10 days. Conidia were collected by flooding plates with sterile nanopore $\mathrm{H}_{2} \mathrm{O}$ with Tween $20(0.5 \% \mathrm{vol} / \mathrm{vol})$, and conidia concentration was determined by hemocytometer counts. Conidia were then added to RO water to a final concentration of $1 \times 10^{4}$ conidia per $1 \mathrm{ml}$, and a hand pressure sprayer was used to deliver approximately $50 \mathrm{ml}$ of the spore suspension to each plant.

Disease observations. Daily disease severity rating began when symptoms were first observed on the flowers, $48 \mathrm{~h}$ after $B$. cinerea inoculation, and continued until 2 weeks after the last treatment application using a 0 to 7 rating scale developed in preliminary trials (Table 2). The daily flower ratings were used to calculate an index of disease (ID) using the following formula, where $n_{x}$ is the number of flowers with a particular severity rating $(x)$ per plant and $N$ is the 
Table 1. Collection of 60 beneficial bacteria evaluated for Botrytis cinerea control in a dual-culture assay and greenhouse trials

\begin{tabular}{|c|c|c|c|c|c|c|}
\hline \multirow[b]{2}{*}{ Bacterial strain } & \multirow[b]{2}{*}{ Bacterial name $\mathrm{a}^{\mathrm{a}}$} & \multirow[b]{2}{*}{ Source } & \multicolumn{3}{|c|}{ Dual-culture assay } & \multirow{2}{*}{$\begin{array}{l}\text { Initial }{ }^{\mathbf{f}} \text { greenhouse trial: } \\
\text { Overall disease severity score }\end{array}$} \\
\hline & & & $\overline{R 1 ~ G R(\%)^{\mathrm{c}}}$ & $R 2$ GR $(\%)^{\mathrm{d}}$ & $R 3(\mathrm{~mm})^{\mathrm{e}}$ & \\
\hline $12 \mathrm{H} 11$ & Pseudomonas protegens & Missouri River & $41.35 \pm 1.12$ & $71.31 \pm 0.42$ & $2.5 \pm 0$ & 2 \\
\hline 14B11 & Pseudomonas chlororaphis & Missouri River & $26.44 \pm 3.66$ & $68.48 \pm 0.13$ & $3.33 \pm 0.6$ & 36 \\
\hline $14 \mathrm{~B} 2$ & Pseudomonas protegens & Missouri River & $45.57 \pm 0.73$ & $70.46 \pm 0.84$ & $4 \pm 0$ & 5 \\
\hline 14D6 & Pseudomonas chlororaphis & Mississippi River & $14.77 \pm 4.15$ & $32.49 \pm 3.45$ & $0 \pm 0$ & 0 \\
\hline MBSA-MJ1h & Serratia plymuthica & Unknown & $31.64 \pm 3.8$ & $62.45 \pm 1.84$ & $0 \pm 0$ & 3 \\
\hline $15 \mathrm{G} 2$ & Pseudomonas protegens & Missouri River & $40.51 \pm 1.93$ & $70.46 \pm 1.52$ & $2.67 \pm 0.33$ & 0 \\
\hline $15 \mathrm{H} 3$ & Pseudomonas protegens & Missouri River & $37.42 \pm 1.24$ & $70.23 \pm 0.98$ & $3.67 \pm 0.33$ & 26 \\
\hline 1B1 & Pseudomonas protegens & Mississippi River & $28.32 \pm 4.97$ & $64.85 \pm 2.5$ & $2.83 \pm 0.44$ & 0 \\
\hline $1 \mathrm{C} 5$ & Pseudomonas protegens & Mississippi River & $22.78 \pm 4.38$ & $43.46 \pm 7.81$ & $0 \pm 0$ & 0 \\
\hline 24D3 & Pseudomonas fluorescens & Herbarium & $17.3 \pm 1.12$ & $59.49 \pm 1.46$ & $0 \pm 0$ & 6 \\
\hline 28B5 & Pseudomonas fluorescens & Herbarium & $13.08 \pm 4.02$ & $59.92 \pm 3.61$ & $0 \pm 0$ & 2 \\
\hline 29G9 & Pseudomonas poae & Herbarium & $7.35 \pm 7.84$ & $73.69 \pm 2.13$ & $4.33 \pm 0.17$ & 0 \\
\hline $2 \mathrm{~F} 9$ & Pseudomonas fluorescens & Missouri River & $34.18 \pm 3.19$ & $64.14 \pm 0.42$ & $0 \pm 0$ & 4 \\
\hline $36 \mathrm{~B} 3$ & Pseudomonas fluorescens & Wyoming soil & $11.33 \pm 5.97$ & $39.49 \pm 3.66$ & $0 \pm 0$ & 0 \\
\hline $36 \mathrm{~B} 7$ & Pseudomonas brassicacearum & Wyoming soil & $16.98 \pm 8.44$ & $71.03 \pm 1.95$ & $4 \pm 0.29$ & 0 \\
\hline $36 \mathrm{C} 6$ & Pseudomonas frederiksbergensis & Wyoming soil & $16.3 \pm 7.47$ & $56.39 \pm 1.84$ & $0 \pm 0$ & 14 \\
\hline $36 \mathrm{C} 8$ & Pseudomonas poae & Wyoming soil & $10.65 \pm 0.9$ & $46.79 \pm 4.83$ & $0 \pm 0$ & 2 \\
\hline $36 \mathrm{D} 4$ & Pseudomonas brassicacearum & Wyoming soil & $10.37 \pm 3.15$ & $70.18 \pm 1.58$ & $4.25 \pm 0.38$ & 0 \\
\hline $36 \mathrm{~F} 3$ & Pseudomonas fluorescens & Wyoming soil & $31.22 \pm 5.68$ & $63.29 \pm 0.73$ & $0.67 \pm 0.67$ & 18 \\
\hline $36 \mathrm{G} 2$ & Pseudomonas fluorescens & Wyoming soil & $19.83 \pm 2.57$ & $57.81 \pm 0.42$ & $0 \pm 0$ & 6 \\
\hline $37 \mathrm{~A} 10$ & Pseudomonas frederiksbergensis & Wyoming soil & $18.99 \pm 4.07$ & $69.2 \pm 0.85$ & $2.5 \pm 0$ & 14 \\
\hline 37D10 & Pseudomonas brassicacearum & Wyoming soil & $2.11 \pm 1.52$ & $25.63 \pm 0.48$ & $0 \pm 0$ & 3 \\
\hline 38D4 & Pseudomonas brassicacearum & Wyoming soil & $16.88 \pm 1.84$ & $33.75 \pm 0.84$ & $0 \pm 0$ & 21 \\
\hline $38 \mathrm{D} 7$ & Pseudomonas brassicacearum & Wyoming soil & $5.07 \pm 4.44$ & $27.46 \pm 3.26$ & $0 \pm 0$ & 0 \\
\hline $38 \mathrm{~F} 7$ & Pseudomonas frederiksbergensis & Wyoming soil & $13.92 \pm 2.63$ & $59.49 \pm 1.93$ & $0 \pm 0$ & 1 \\
\hline $38 \mathrm{G} 2$ & Pseudomonas protegens & Wyoming soil & $28.22 \pm 1.63$ & $69.51 \pm 0.41$ & $3.17 \pm 0.33$ & 23 \\
\hline 39A2 & Pseudomonas frederiksbergensis & Wyoming soil & $9.96 \pm 2.12$ & $67.25 \pm 0.61$ & $3 \pm 0.29$ & 7 \\
\hline $48 \mathrm{~B} 8$ & Pseudomonas chlororaphis & Wyoming soil & $24.78 \pm 0.73$ & $67.22 \pm 0.85$ & $3.17 \pm 0.17$ & 0 \\
\hline MBSA-3BB $1^{\mathrm{h}}$ & Pantoea agglomerans & Unknown & $18.37 \pm 5.32$ & $44.49 \pm 6.55$ & $0 \pm 0$ & 33 \\
\hline $48 \mathrm{D} 1$ & Pseudomonas fluorescens & Wisconsin soil & $11.81 \pm 6.22$ & $62.17 \pm 1.59$ & $0 \pm 0$ & 0 \\
\hline 48G9 & Pseudomonas chlororaphis & Wisconsin soil & $21.44 \pm 3.37$ & $64.28 \pm 1.23$ & $1.17 \pm 0.22$ & 8 \\
\hline $48 \mathrm{H} 11$ & Pseudomonas brassicacearum & Wisconsin soil & $-0.87 \pm 0.87$ & $13.14 \pm 5.53$ & $0 \pm 0$ & 0 \\
\hline $88 \mathrm{~A} 6$ & Pseudomonas rhodesiae & Missouri soils & $9.34 \pm 1.8$ & $31.49 \pm 0.6$ & $0 \pm 0$ & 6 \\
\hline $89 \mathrm{~F} 1$ & Pseudomonas fluorescens & Missouri soils & $17.72 \pm 4.38$ & $34.18 \pm 4.07$ & $0 \pm 0$ & 26 \\
\hline 90D7A & Pseudomonas fluorescens & Missouri soils & $6.31 \pm 4.59$ & $15.73 \pm 5.47$ & $0 \pm 0$ & 10 \\
\hline $90 \mathrm{~F} 12-1$ & Pseudomonas rhodesiae & Missouri soils & $17.02 \pm 1.1$ & $37.39 \pm 2.51$ & $0 \pm 0$ & 4 \\
\hline $90 \mathrm{~F} 12-2$ & Pseudomonas fluorescens & Missouri soils & $9.68 \pm 6.24$ & $15.05 \pm 11.2$ & $0 \pm 0$ & 5 \\
\hline $93 \mathrm{~F} 8$ & Pseudomonas brassicacearum & Missouri soils & $45.99 \pm 2.57$ & $72.57 \pm 0.42$ & $3.33 \pm 0.17$ & 0 \\
\hline 94G2 & Pseudomonas frederiksbergensis & Missouri soils & $12.62 \pm 3.21$ & $55.88 \pm 0.75$ & $0 \pm 0$ & 75 \\
\hline Clinton & Pseudomonas protegens & Ohio soil & $20.94 \pm 1.64$ & $63.58 \pm 1.2$ & $1.33 \pm 0.33$ & 0 \\
\hline Darke & Pseudomonas protegens & Ohio soil & $28.88 \pm 9.12$ & $64.42 \pm 1.82$ & $1.67 \pm 0.33$ & 7 \\
\hline Delaware & Pseudomonas brassicacearum & Ohio soil & $35.02 \pm 1.12$ & $62.87 \pm 1.52$ & $0.75 \pm 0.25$ & 0 \\
\hline Wayne & Pseudomonas protegens & Ohio soil & $29.96 \pm 6.39$ & $66.24 \pm 1.52$ & $2.17 \pm 0.44$ & 11 \\
\hline Wood 1 & Pseudomonas brassicacearum & Ohio soil & $31.49 \pm 2.49$ & $68.48 \pm 2.01$ & $3.67 \pm 0.17$ & 0 \\
\hline Wood 3 & Pseudomonas brassicacearum & Ohio soil & $27.75 \pm 3.42$ & $66.38 \pm 1.24$ & $1.25 \pm 0.14$ & 1 \\
\hline AP1 & Pseudomonas putida & Dr. J. Kloepper & $15.19 \pm 3.19$ & $34.6 \pm 2.95$ & $0 \pm 0$ & 0 \\
\hline AP19 & Pseudomonas putida & Dr. J. Kloepper & $5.91 \pm 2.23$ & $30.38 \pm 0.73$ & $0 \pm 0$ & 8 \\
\hline AP20 & Pseudomonas putida & Dr. J. Kloepper & $18.14 \pm 2.57$ & $41.77 \pm 4.07$ & $0 \pm 0$ & 0 \\
\hline $\mathrm{AP} 22$ & Phyllobacterium rubiacearum & Dr. J. Kloepper & $0 \pm 0$ & $27 \pm 1.11$ & $0 \pm 0$ & 0 \\
\hline $\mathrm{AP} 24$ & Phyllobacterium rubiacearum & Dr. J. Kloepper & $2.95 \pm 2.95$ & $26.16 \pm 2.23$ & $0 \pm 0$ & 0 \\
\hline AP28 & Pseudomonas chlororaphis & Dr. J. Kloepper & $59.49 \pm 9.5$ & $81.43 \pm 3.38$ & $0 \pm 0$ & 1 \\
\hline AP35 & Ochrobactrum anthropi & Dr. J. Kloepper & $9.71 \pm 4.98$ & $30.38 \pm 5.71$ & $0 \pm 0$ & 0 \\
\hline AP36 & Ochrobactrum anthropi & Dr. J. Kloepper & $0 \pm 0$ & $20.25 \pm 2.19$ & $0 \pm 0$ & 6 \\
\hline $\mathrm{AP} 47^{\mathrm{h}}$ & Rhizobium tropici & Dr. J. Kloepper & $0 \pm 0$ & $24.47 \pm 1.52$ & $0 \pm 0$ & 26 \\
\hline AP5 $4^{\mathrm{h}}$ & Pseudomonas protegens & Dr. J. Kloepper & $17.72 \pm 1.93$ & $48.1 \pm 1.93$ & $0 \pm 0$ & 39 \\
\hline AP56 & Comamonas acidovorans & Dr. J. Kloepper & $36.71 \pm 3.35$ & $70.46 \pm 1.52$ & $4.17 \pm 0.83$ & 0 \\
\hline AP58 & Comamonas acidovorans & Dr. J. Kloepper & $46.41 \pm 5.49$ & $75.95 \pm 0$ & $5.17 \pm 0.67$ & 6 \\
\hline AP59 & Comamonas acidovorans & Dr. J. Kloepper & $46.83 \pm 1.27$ & $73.42 \pm 0.73$ & $4.67 \pm 0.33$ & 0 \\
\hline AP187 & Yersinia frederiksenii & Dr. J. Kloepper & $24.47 \pm 0.85$ & $58.65 \pm 0.42$ & $0 \pm 0$ & 18 \\
\hline AP222 & Pseudomonas putida & Dr. J. Kloepper & $11.39 \pm 1.93$ & $26.16 \pm 2.57$ & $0 \pm 0$ & 0 \\
\hline NA & Cycloheximide solution ${ }^{\mathrm{i}}$ & NA & $39.96 \pm 0.61$ & $63.01 \pm 0.91$ & $3.24 \pm 0.31$ & NA \\
\hline QST 713 & Bacillus subtilis ${ }^{\mathrm{j}}$ & Cease & NA & NA & NA & 12 \\
\hline NA & Negative control $^{\mathrm{k}}$ & NA & $0 \pm 0$ & $0 \pm 0$ & $0 \pm 0$ & NA \\
\hline
\end{tabular}

a All strains except those from Ohio soils and Dr. J. Kloepper were first described by Aly (2009) and Subedi et al. (2019). Strains from Ohio soils were described by McSpadden Gardener et al. (2005). $\mathrm{b} B$. cinerea mycelial growth and zone of inhibition were recorded in the dual-culture assay for each bacterial treatment replicated three times.

c The mean percentage growth reduction (GR) of mycelium parallel to bacterial streak $(R 1) \pm$ standard error from the dual-culture assay.

$\mathrm{d}$ The mean percentage growth reduction of mycelium perpendicular to the bacterial streak $(R 2) \pm$ standard error from the dual-culture assay.

e The zone of inhibition (millimeters) distance from the leading edge of the $B$. cinerea mycelium to the edge of the bacterial streak \pm standard error from the dual-culture assay.

f The 60 bacterial strains were evaluated on petunia plants along with positive control (Bacillus subtilis QST 713) and negative control (no bacteria). All open flowers were tagged before B. cinerea inoculation and rated daily using a disease severity scale ( 0 : no symptoms; 7 : senesced because of $B$. cinerea) (Table 2 ). Each bacterial treatment was replicated 3 times, whereas both controls were replicated 12 times.

${ }^{\mathrm{g}}$ In the initial greenhouse trial, the score was given to bacterial treatments considering how often each strain appeared in the top 10-ranked bacteria on each rating day. Rank was determined from the fixed effect estimates of treatment effect on rating compared with the negative control (Supplementary Table S1).

h Identity of strains is based on the results of genome sequencing and percentage taxonomy by CoreBiome 2019.

i Cycloheximide (58.6 mM in ethanol) was used as the positive control in the dual-culture assay. NA = not applicable.

$\mathrm{j}$ Bacillus subtilis QST 713 was used as the positive control in the greenhouse trials.

$\mathrm{k}$ The negative control treatment contained no bacteria. 
total number of flowers per plant (Horiuchi and Hori 1980; Strelkov et al. 2006):

$$
I D(\%)=\frac{\sum\left(\left(n_{0} \times 0\right)+\left(n_{1} \times 1\right)+\left(n_{2} \times 2\right)+\left(n_{3} \times 3\right)+\left(n_{4} \times 4\right)+\left(n_{5} \times 5\right)+\left(n_{6} \times 6\right)+\left(n_{7} \times 7\right)\right)}{N \times 7} \times 100 \%
$$

Greenhouse validation trial. Experimental design. The seven top-performing strains selected from the initial greenhouse trial were used in the greenhouse validation trial. The same negative (sterile LB medium) and positive (Bacillus subtilis QST 713) controls were used in these experiments. The validation trial was conducted twice using a randomized complete block design with 12 replicates of each treatment. Plant material, bacteria treatments, pathogen inoculation, and daily disease severity ratings were the same as described above for the initial greenhouse trial.

Environmental data. Environmental data inside the tents were collected using a weather station (Watchdog Mini Weather Station; Spectrum Technologies, Inc., Plainfield, IL) that took measurements every $30 \mathrm{~min}$. The daily average photosynthetic active radiation (PAR) light (Fig. 2A), relative humidity (Fig. 2B), and temperature (Fig. 2C) were calculated for a 24-h period for each day (days 1 to 12 ) after $B$. cinerea inoculation. Data were collected every $30 \mathrm{~min}$ from time of inoculation (day 0) to project termination (day 12) for daily average PAR light (micromoles per meter $^{2}$ per second) (Fig. 2A), daily average relative humidity (percentage) (Fig. 2B), and daily average temperature (degrees Celsius) (Fig. 2C). Day 0 measurements began at 18:30. All other days are an average of a 24-h period (Fig. 2).

Statistical analysis. Dual-culture assay. All statistical analyses were done in R (R Foundation for Statistical Computing, Vienna, Austria). A principal component analysis using the princomp function (R Core Team 2019) was conducted for the $R 1$ and $R 2$ growth measurement values, and a principal component was selected to use as the response variable for analysis of variance. All treatments were compared with the negative control using Dunnett's Comparison.

Initial greenhouse trial. The calculated index of disease was used to select the top-performing bacteria. Square root transformation was used to transform the index of disease. The transformed data were then analyzed with lme4 (Bates et al. 2015) using a fit linear mixed effects model. Fixed effect estimates of treatment effect on rating day

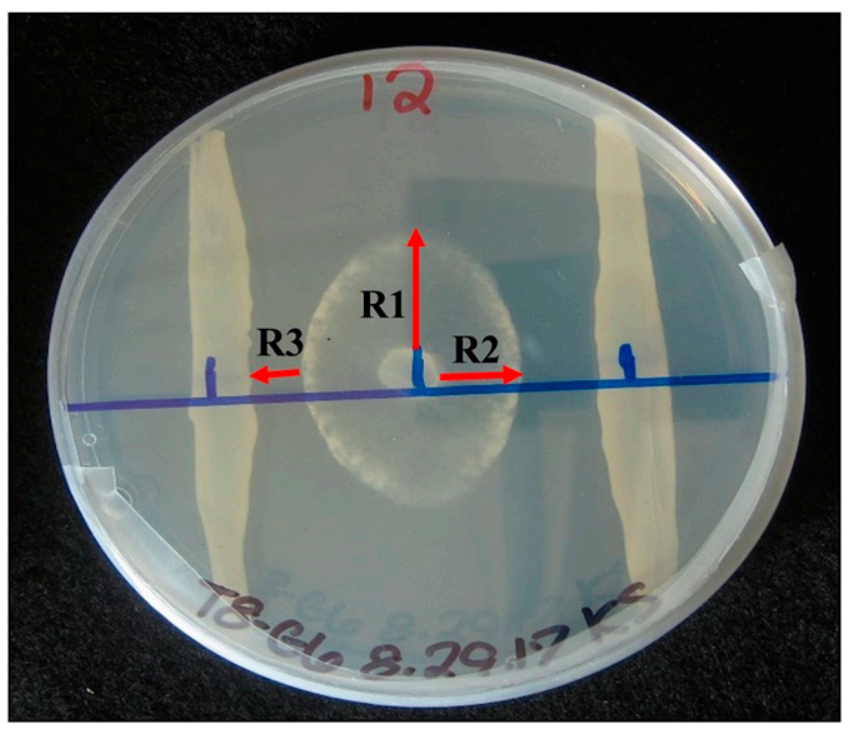

Fig. 1. Dual-culture assay measurements defined. A dual-culture assay was used to evaluate the collection of 60 bacterial strains. A Botrytis cinerea mycelial plug was placed in the center of a petri dish, and each bacterial strain was streaked $2.5 \mathrm{~cm}$ away from the plug along both sides. The growth of the mycelium was measured parallel $(R 1)$ and perpendicular $(R 2)$ to the bacterial streak. The zone of inhibition $(R 3)$, which is the distance from the leading edge of the $B$. cinerea mycelium to the edge of the bacterial streak, was also measured. (days 2 to 12) were used to rank the treatments compared with the negative control for each rating day. A scoring system that considered how often each strain appeared in the top 10 ranking for each day was used to select the top-performing strains. If the strain ranked first in day 2 , it received 10 points, and if it ranked sixth in day 3 , it received 5 points and so on. These points were then added together for all rating days to get the overall disease severity score.

Greenhouse validation trial. The daily ratings collected for the validation trials were used to calculate the area under the disease progress curve (AUDPC) (Shaner and Finney 1977). The square root-transformed AUDPC was analyzed using a fit linear model. The daily ratings were also used to calculate the index of disease, and they were analyzed as described for the initial greenhouse trial.

\section{Results}

Dual-culture assay. Twenty of the 60 bacterial strains evaluated in the dual-culture assay resulted in a $\geq 25 \% R 1$ growth reduction (GR) of $B$. cinerea, and 36 strains resulted in a $\geq 50 \% R 2$ growth reduction (Table 1). AP2 8 resulted in the highest $R 1$ and $R 2$ growth reductions at $59.49 \pm 9.50 \%$ and $81.43 \pm 3.38 \%$, respectively. However, not all strains followed a pattern of having similar $R 1$ and $R 2$ percentage growth reductions. For example, 29G9 resulted in one of the highest $R 2$ growth reductions at $73.69 \pm 2.13 \%$ but one of the lowest $R 1$ growth reductions of $7.35 \pm 7.84 \%$. Strain $48 \mathrm{H} 11$ resulted in the lowest growth reduction for both $R 1(-0.87 \pm$ $0.87 \%)$ and $R 2(13.14 \pm 9.58 \%)$. For $R 3$ measurements, 35 of the tested strains had no zone of inhibition. Of those strains that did have a zone of inhibition, the largest $R 3$ value was $5.2 \mathrm{~mm}$ for AP58, and the smallest $R 3$ value was $0.67 \mathrm{~mm}$ for $36 \mathrm{~F} 3$ (Table 1 ).

The principal component used to compare the treatments with the negative control accounted for $99 \%$ of variance. Although 56 strains had a negative estimate, only 35 bacterial strains were statistically different from the negative control based on Dunnett's test at $P<$ 0.001 (Fig. 3). Among these were seven strains (AP28, AP59, AP58, 93F8, 14B2, 12H11, and 15G2) that performed better than the positive control. Of these 35 bacteria, only 22 had a zone of inhibition (R3) (Table 1). Four strains (48H11, AP22, AP47, and AP36) had positive estimated values, showing that there was no reduced $B$. cinerea mycelial growth compared with the negative control. Eight treatments that resulted in both mycelial growth reduction and a large zone of inhibition were AP59, AP58, 93F8, 14B2, 15H3, AP56, Wood 1, and 36B7 (Table 1).

Initial greenhouse trial for bacterial strain selection. The disease severity index fixed effect estimates of treatment effect on rating day were used to select the top-performing bacteria (Fig. 4). The negative values indicate treatments that performed better than the negative control (less disease), and positive values indicate treatments that performed worse. Looking at 2, 6, and 12 days after the $B$. cinerea inoculation, a majority of the bacterial strains resulted in less gray mold on the plants compared with the negative control. On day 12, 10 bacterial strains performed better than the positive control, Bacillus subtilis QST 713 (Fig. 4C).

Table 2. Disease severity rating scale used for Botrytis cinerea infection in petunia flowers

\begin{tabular}{ll}
\hline Rating & \multicolumn{1}{c}{ Symptoms } \\
\hline 0 & No disease \\
1 & $\leq 5$ small lesions \\
2 & $>5$ small lesions \\
3 & Medium-sized lesions \\
4 & Large lesions or medium-sized lesions \\
& scattered across the flower \\
5 & Half or more of the flower is covered in \\
& lesions \\
6 & The flower is starting to senesce because of \\
7 & B. cinerea \\
& The flower is senesced or detached because of \\
& B. cinerea \\
\hline
\end{tabular}


Seven top-performing strains were identified based on an overall disease severity score. The overall disease severity score was calculated using the daily ranking of the strain based on the disease severity index fixed effect estimates of treatment effect on rating day. For example, strain $94 \mathrm{G} 2$ received 8 points for day 3,10 points for day 4 , and so on to receive an overall disease severity score of 75 (Table 1 and Supplementary Table S1). The higher score indicated that a treatment resulted in plants with less disease across more days compared with the other treatments (Table 1). Strains AP54, 14B11, and MBSA-3BB1 received overall disease severity scores of 39,36 , and 33 , respectively, whereas strains $89 \mathrm{~F} 1,15 \mathrm{H} 3$, and AP47 all had scores of 26. The positive control had a score of only 12 (Table 1).

Plants treated individually with the seven top-performing strains had reduced disease severity compared with those treated with the negative control (no bacteria) (Fig. 5). Six days after rating, plants

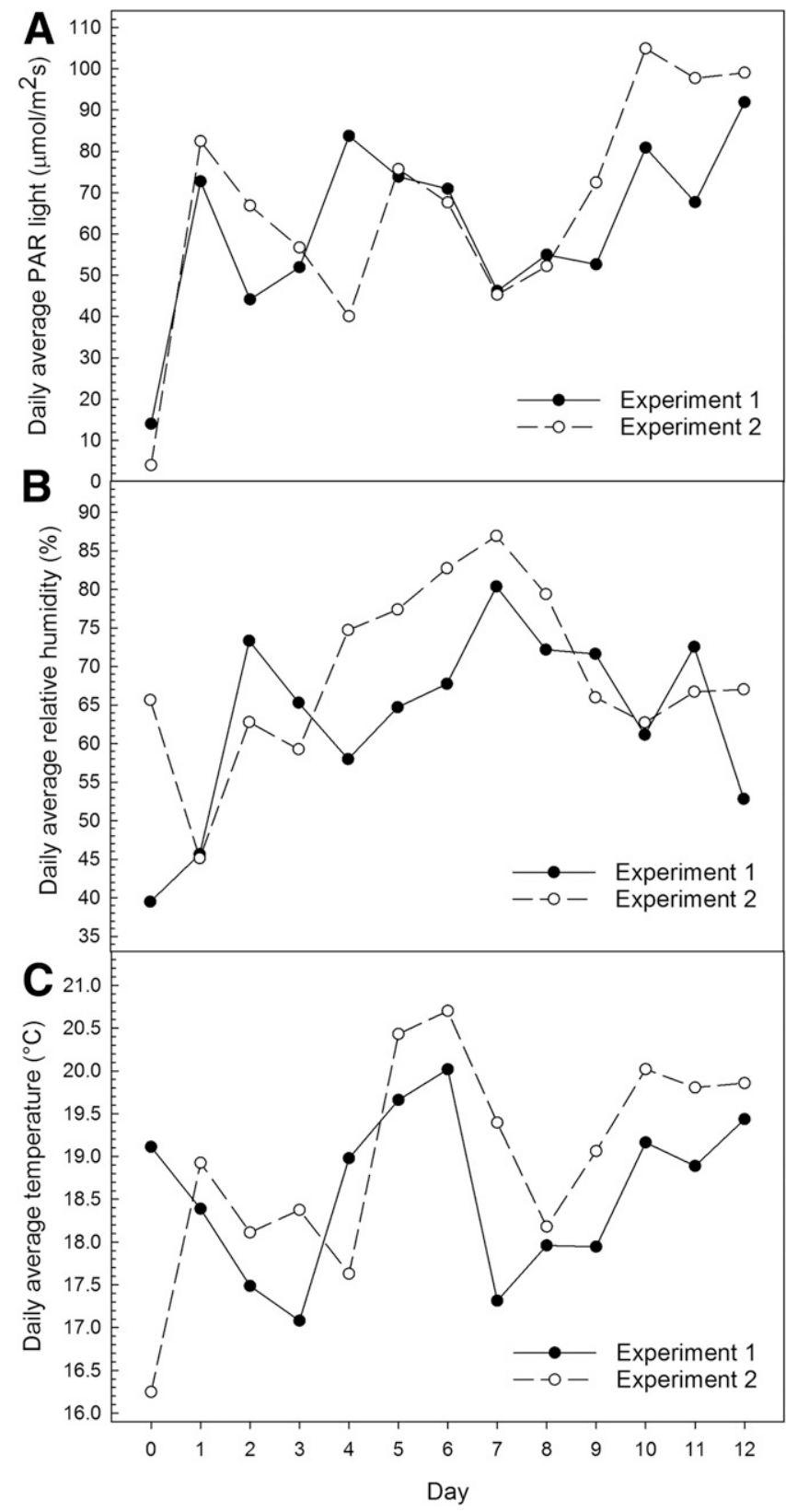

Fig. 2. Environmental data for the greenhouse validation trial. Solid lines and black circles represent experiment 1 , and dashed lines and white circles represent experiment 2. Data were collected every $30 \mathrm{~min}$ from time of inoculation (day 0 ) to project termination (day 12) for $\mathbf{A}$, daily average photosynthetic active radiation (PAR) light (micromoles per meter ${ }^{2}$ per second); $\mathbf{B}$, daily average relative humidity (percentage); and $\mathbf{C}$, daily average temperature (degrees Celsius). Day 0 measurements began at 18:30. All other days are an average of a 24-h period. treated with the top strains $(94 \mathrm{G} 2[20.90 \pm 5.36]$, AP54 $[29.45 \pm$ 11.15], 14B11 [22.23 \pm 7.94], MBSA-3BB1 [23.98 \pm 4.59 ], 89F1 $[44.13 \pm 6.51], 15 \mathrm{H} 3[29.13 \pm 5.95]$, and AP47 [28.20 \pm 10.40$])$ and the positive control $(29.47 \pm 3.06)$ had reduced disease severity indices compared with the negative control plants $(50.85 \pm 4.20)$. Strain 94G2 resulted in the highest disease reduction, with a 59\% decrease in the disease severity index compared with negative control plants, whereas plants treated with $89 \mathrm{~F} 1$ had a $13 \%$ decrease. Negative control plants continued to have a higher disease severity index compared with those treated with either one of the top seven strains or the positive control through the last rating day. On the last day of rating, plants treated with 94G2, AP54, 14B11, MBSA-3BB1, 89F1, $15 \mathrm{H} 3$, or AP47 had a lower disease severity index compared with the negative control $(78.42 \pm 3.42)$, with indices of $56.51 \pm 15.38$, $52.94 \pm 10.76,38.89 \pm 3.97,59.05 \pm 12.38,55.40 \pm 0.88,42.78 \pm$ 6.16 , and $62.86 \pm 3.60$, respectively. Positive control plants were comparable with the bacterial treatments, with a disease severity index of $55.47 \pm 3.55$ (Fig. 5). Strain 14B11 resulted in the highest disease reduction, with a $50 \%$ reduction in the disease severity index compared with negative control plants, whereas plants treated with AP47 had a $19 \%$ reduction.

Greenhouse validation trial. All seven strains selected from the initial greenhouse trial reduced disease severity on treated plants in the validation trial. There was a bacterial treatment effect on AUDPC $(P=0.0013)$ (Fig. 6). Dunnett's test was used to determine that 14B11 $(P=0.0449)$, AP54 $(P=0.0073)$, and the positive control $(P=0.001)$ had reduced disease severity over the rating period with AUDPC values of $44.92 \pm 2.72,42.94 \pm 2.43$, and $41.18 \pm 2.29$, respectively (Fig. 6). The negative control had an AUDPC of $51.07 \pm$ 1.91. Strains 89F1, 94G2, 15H3, AP47, and MBSA-3BB1 had lower but not significantly different AUDPC values of $45.59 \pm 2.16(P=$ 0.107), $46.57 \pm 2.30(P=0.201), 48.65 \pm 1.86(P=0.571), 49.49 \pm$ $1.67(P=0.718)$, and $49.98 \pm 2.47(P=0.720)$, respectively, when compared with the negative control (Fig. 6).

The disease severity index fixed effect estimates of treatment effect on rating day were also used to identify the top-performing strains among the seven tested (Fig. 7). Strain 89F1 reduced disease severity more than the positive control on day 2 (Fig. 7A), and then, it remained in the top four strains for disease reduction through day 12 (Fig. 7C). Strain AP54 was one of the top two strains on each rating day. Strain 14B11 appeared in the top three strains on day 2 (Fig. 7A) and remained in the top three strains through the last day of rating. Strain MBSA-3BB1 had a higher disease severity index than the negative control on day 2 , but then, it had a reduced disease severity index compared with the negative control by day 6 . Strains $15 \mathrm{H} 3$ and AP47 had reduced disease severity compared with the negative control each rating day. In the estimate rankings, 94G2 was among the top three strains on day 12 (Fig. 7C).

The three top-performing strains selected through calculating the AUDPC and daily disease severity index were AP54, 14B11, and 89F1. Plants treated with AP54 or 14B11 had a reduced AUDPC value (Fig. 6) and disease severity index (Fig. 7). Although plants treated with $89 \mathrm{~F} 1$ did not have a significant decrease in AUDPC values, there was a consistent reduction in the disease severity index compared with the negative control.

These three strains had a decreased disease severity index across all rating days. Considering the two validation experiments, the extent of the reduction in disease severity varied because of the recorded environmental conditions (Fig. 2). Compared with experiment 1 , the average relative humidity was higher and the average temperature was lower in experiment 2 , which are conditions more conducive to $B$. cinerea infection. This environmental effect is reflected in the disease severity index. For example, the negative control in experiment 1 on day 2 had a disease severity index of $20.39 \pm$ 1.75 , and the positive control had a disease severity index of $13.32 \pm$ 1.81 (Fig. 8A). In experiment 2 on day 2, the negative control had a disease severity index of $31.31 \pm 3.57$, whereas the positive control had a disease severity index of $21.66 \pm 2.67$ (Fig. 8B). In experiment 1 , there was a clear separation of the treatments by day 7 , where the top three strains resulted in disease severity indices in a range 
between the negative $(72.96 \pm 4.65)$ and positive $(54.45 \pm 4.34)$ controls (Fig. 8A). Disease progressed faster in experiment 2 because clear separation in the treatments was observed by day 3 , where the top three strains resulted in disease severity indices in a range between the negative $(46.50 \pm 4.43)$ and positive $(34.41 \pm 3.33)$ controls. By day 12 in experiment 1 , the positive control plants had a $27 \%$ reduction in the disease severity index compared with the negative control, whereas the disease severity indices were reduced by 18,19 , and $14 \%$ for AP54, 14B11, and 89F1, respectively. By day 12 in experiment 2 , positive control plants had only a $7 \%$ reduction in disease severity index compared with the negative control, whereas there were reductions of 10,2 , and $1 \%$ for AP54, 14B11, and $89 \mathrm{~F} 1$, respectively (Fig. 8).

\section{Discussion}

Biocontrol products give growers additional tools to manage pathogens, and biocontrol options are especially needed for $B$. cinerea because it is becoming increasingly resistant to chemical fungicides (Muñoz et al. 2019). Beneficial bacteria have previously shown potential as biocontrol agents in the management of gray mold (Barka et al. 2002; Yildiz et al. 2007), specifically in greenhouse floriculture crops (Gould et al. 1996; Redmond et al. 1987). This study aimed to identify potential biocontrol agents from a collection of 60 bacterial strains for the control of gray mold in greenhouse floriculture crops. The original bacterial collection was evaluated in a dual-culture assay, where 35 strains were selected as top performers for the reduction of $B$. cinerea in vitro along with an initial greenhouse trial where seven strains were selected as top performers for the reduction of gray mold severity in planta. The seven top-performing strains from the initial greenhouse trial were then evaluated in the greenhouse validation trial, and three top-performing strains (Pseudomonas fluorescens
89F1, Pseudomonas chlororaphis 14B11, and Pseudomonas protegens AP54) were selected.

In vitro inhibition assays are often used as an initial method to narrow down a collection of potential antagonists (Kefi et al. 2015) or to further characterize a collection (Trotel-Aziz et al. 2008). In this study, 60 previously identified beneficial bacteria were characterized for the ability to reduce $B$. cinerea growth in a dual-culture assay, but this was not used as the sole method for selecting top-performing bacteria. The mycelial growth $(R 1$ and $R 2)$ reduction and zone of inhibition can be attributed to antifungal compound production by antagonists, such as antibiotics (like 2, 4-diacetophluoroglucinol), enzymes (like chitinase), or volatiles (like hydrogen cyanide), that can inhibit growth of a plant pathogen (Kerr 1999). Specifically, a zone of inhibition is a good indicator of antifungal compound production (Chand and Logan 1984; Köhl et al. 2019; Royse and Ries 1978).

Twenty-five strains had zones of inhibition, whereas a few strains, like Pseudomonas protegens AP58, had both a large mycelial growth reduction ( $R 1$ and $R 2)$ and a large zone of inhibition, indicating the potential for antifungal compound production. A reduction in mycelial growth with no zone of inhibition is an indication of varying growth rates between the antagonist and the pathogen (Fokkema 1973). Pseudomonas chlororaphis AP28 had the largest mycelial growth reduction $(R 1$ and $R 2$ ) with no zone of inhibition. Wang et al. (2009) evaluated 238 bacterial isolates in an in vitro assay against $B$. cinerea and used the zone of inhibition and rate of inhibition (based on $R 1$ and $R 2$ ) to select three bacteria to be further evaluated. These three strains were evaluated on detached tomato leaves, and one Bacillus subtilis strain was identified based on the reduction in lesion diameter on leaves treated with the strain compared with the untreated control. Using a similar selection criterion in our study, only 8 strains of 60 had both a zone of inhibition and reduced

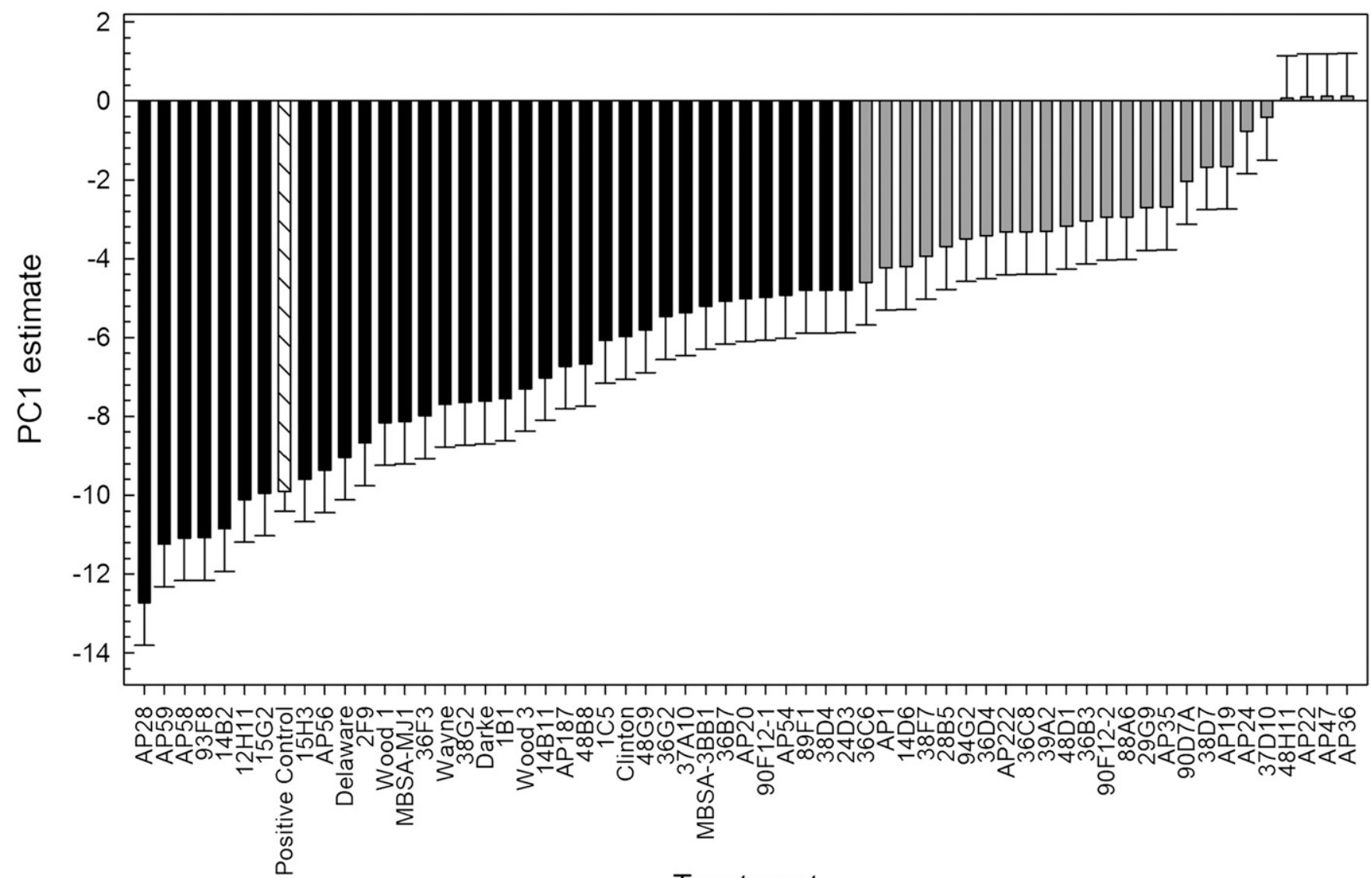

Treatment

Fig. 3. Estimates from selected principal components (PCs) compared with the negative control. A PC analysis was conducted with the two Botrytis cinerea growth measurements from the dual-culture assay, growth of the mycelium measured parallel $(R 1)$ and perpendicular $(R 2)$ to the bacterial streak. The selected PC was used to do a Dunnett's Comparison of the 60 bacterial strains and the positive control (cycloheximide solution) with the negative control (no bacteria). Treatments that reduced the $B$. cinerea growth compared with the negative control have a negative value, whereas those that did not have a positive value. Black bars are different than the negative control with $P<0.001$, and the white bar with slanted lines represents the positive control. Those treatments not different from the negative control $(P>0.001)$ are gray. The error bars denote standard error. 
mycelial growth (Table 1). Careful conclusions must be drawn from the dual-culture assay because it has been shown that growth media type can affect the antagonist's antibiotic production (Whipps 1987). Also, this zone of inhibition could be a result of metabolite production by the pathogen, which is induced by the antagonist instead of from the antagonist itself (Fokkema 1973).
The full collection of bacteria was also evaluated in the initial greenhouse trial for the strains' ability to reduce $B$. cinerea infection in a greenhouse production setting, which accounts for the plant, microbe, and environment interactions needed for successful biocontrol efficacy (Pal and McSpadden Gardener 2006). Flowers were evaluated daily for disease severity because they are more susceptible to
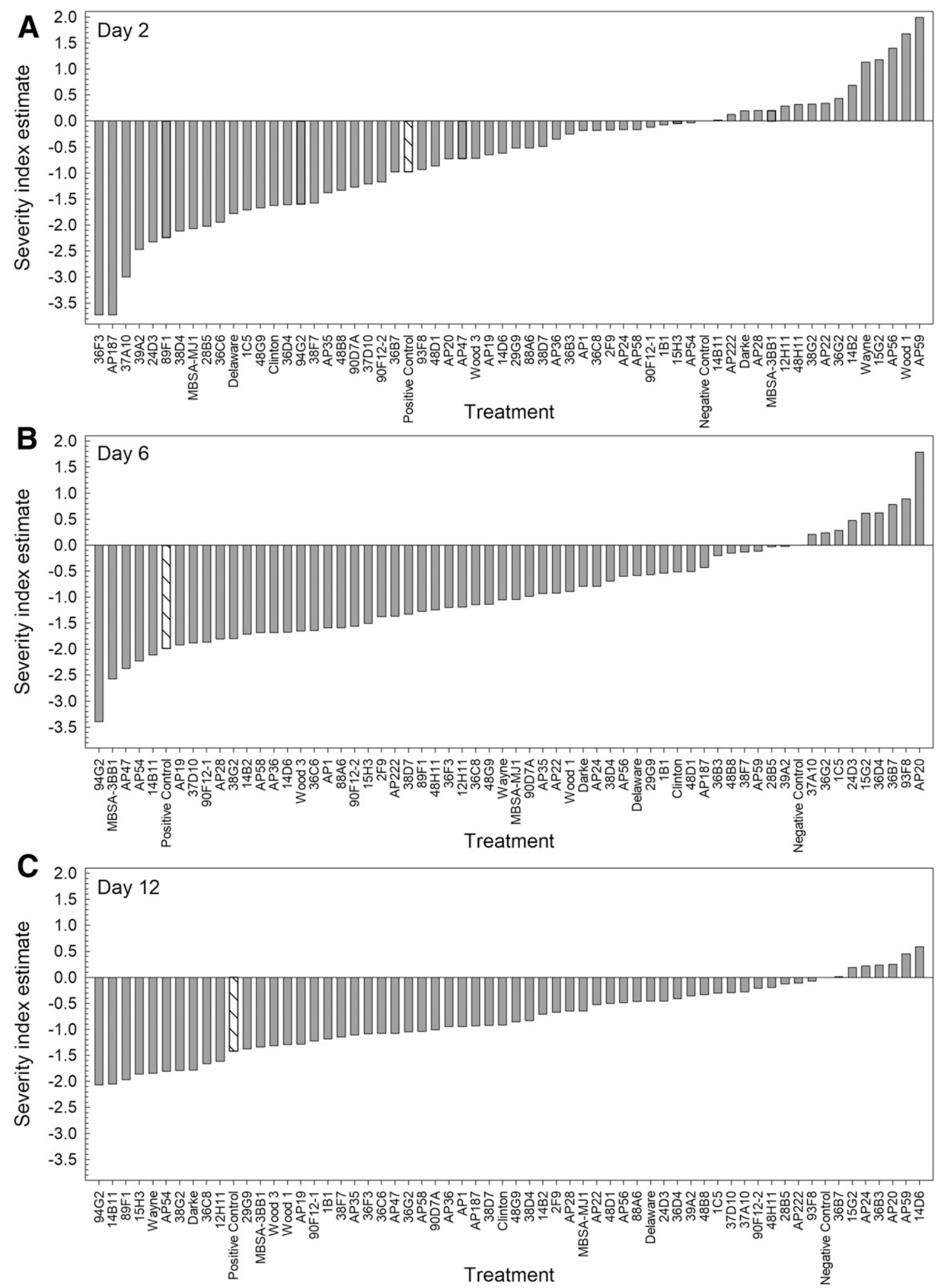

Fig. 4. Initial greenhouse trial disease severity index treatment effects compared with the negative control. Treatment effects compared with the negative control for A, day 2; $\mathbf{B}$, day 6 ; and $\mathbf{C}$, day 12 were extracted from the linear mixed effects model used with the square root-transformed disease severity index data. The 60 bacterial strains and positive control (Bacillus subtilis QST 713) were compared with the negative control (no bacteria). Negative values indicate the treatments that resulted in reduced disease severity compared with the negative control, whereas the positive values mean that the plants had a higher disease severity. The positive control is represented by the white bars with slanted lines. Each treatment was replicated three times, whereas the controls were replicated 12 times each. 
B. cinerea infection than vegetative tissues (Dik and Wubben 2007). Seven bacteria were identified that reduced gray mold severity on petunia flowers. Plants treated with the top seven bacterial strains had consistently reduced disease severity compared with the negative control plants. Some bacterial treatments also performed as well or better than the commercial biopesticide used as the positive control (Bacillus subtilis QST 713). The reduction in gray mold on flowers after application of beneficial organisms supports what has been reported in previous studies with cut roses sprayed with yeast or bacteria (Redmond et al. 1987) and petunia flowers sprayed with bacteria (Gould et al. 1996).

In our study, the dual-culture assay did not predict the topperforming strains identified through the initial greenhouse trial.

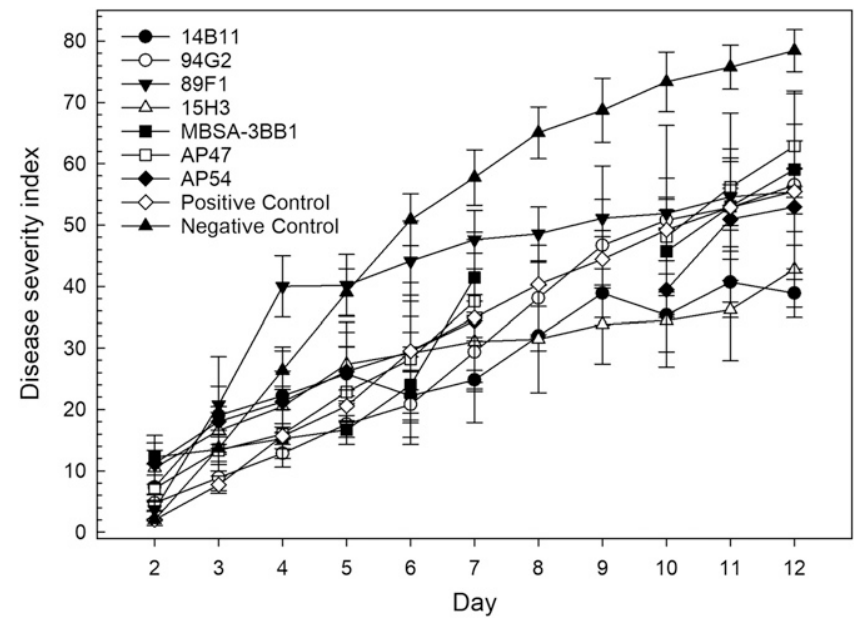

Fig. 5. Initial greenhouse trial disease severity index across all rating days of the seven top-performing strains. The disease severity index was calculated using the daily ratings of individual flowers. Plants were rated daily for 11 days. The negative control (no bacteria) is represented with the black upright triangle, and the positive control (Bacillus subtilis QST 713) is represented by the white diamond. Each bacterial treatment was replicated three times, whereas the controls were replicated 12 times each. The error bars denote standard error.

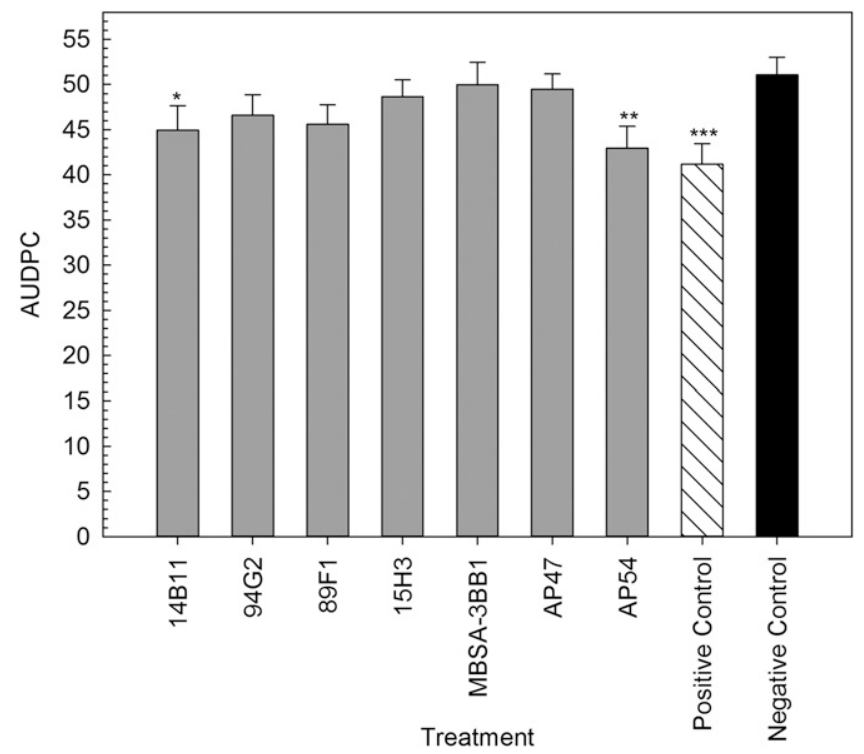

Fig. 6. Area under the disease progress curve (AUDPC) calculated from severity ratings collected during the greenhouse validation trial. Treatment effects compared with the negative control extracted from the linear mixed effects model used with the square root-transformed AUDPC data. The positive control (Bacillus subtilis QST 713) is represented by the white bar with slanted lines. The negative control (no bacteria) is represented by the black bar. Each treatment was replicated 12 times. Error bars show standard error, and asterisks indicate significance. ${ }^{*} P \leq$ $0.05 ;{ }^{* *} P \leq 0.01 ;{ }^{* \star *} P \leq 0.001$.
Pantoea agglomerans MBSA-3BB1, Pseudomonas protegens AP54, Pseudomonas fluorescens 89F1, Pseudomonas frederiksbergensis 94G2, and Rhizobium tropici AP47 did not have a zone of

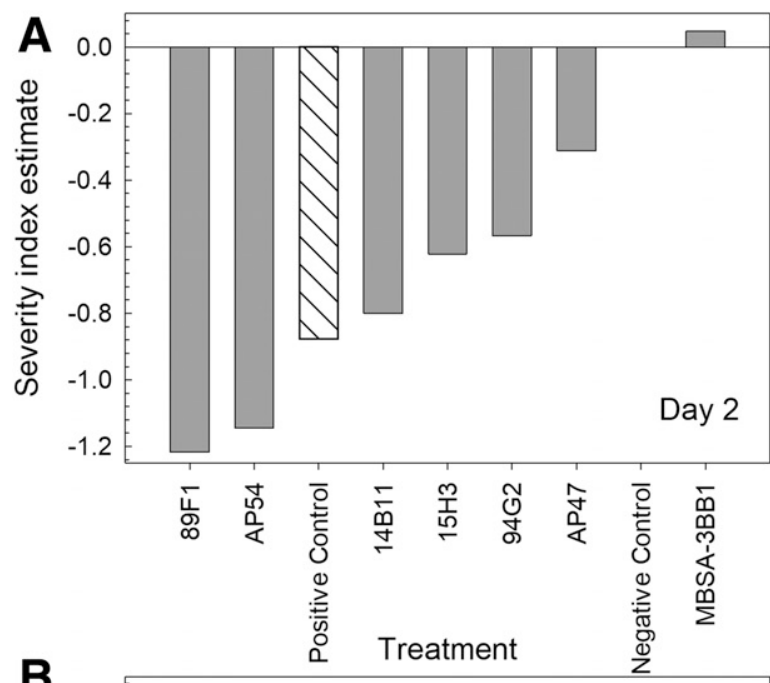

B
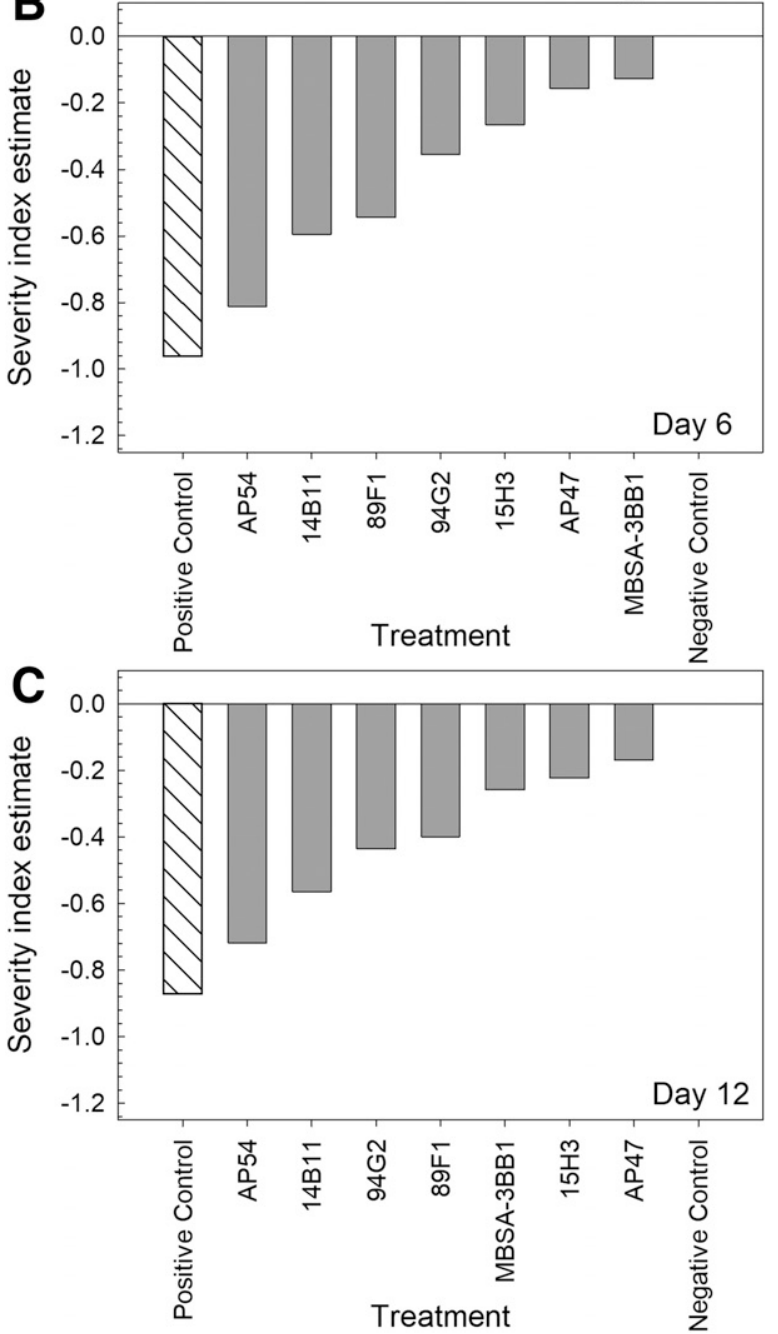

Fig. 7. Disease severity index treatment effects compared with the negative control for greenhouse validation trial. Treatment effects compared with the negative control for $\mathbf{A}$, day 2 ; $\mathbf{B}$, day 6 ; and $\mathbf{C}$, day 12 were extracted from the linear mixed effects model used with the square root-transformed disease severity index data. The seven bacterial strains and positive control (Bacillus subtilis QST 713) were compared with the negative control (no bacteria). Negative values indicate the treatments that resulted in reduced disease severity compared with the negative control, whereas the positive values mean that the plants had a higher disease severity. The positive control is represented by the white bars with slanted lines. Each treatment was replicated 12 times. 
inhibition in the dual-culture assay. Only Pseudomonas chlororaphis 14B11 and Pseudomonas protegens $15 \mathrm{H} 3$ had a zone of inhibition. Pseudomonas protegens $15 \mathrm{H} 3$ was the only one of the top seven strains that was selected as a top performer in the dual-culture assay for both zone of inhibition and reduction of mycelial growth. Similarly, in a study with wheat, selected beneficial bacteria from a growth chamber assay were evaluated for the control of Pythium spp. through both an in vitro assay and a field study. They found that, although the top-performing strains from the field study showed growth reduction of most Pythium spp. tested, the best-performing bacteria in the in vitro assay were not the most effective in the field (Milus and Rothrock 1997).

Using in planta studies as a screening method is challenging in some cases because of the size of the bacterial collection of interest. Gould et al. (1996) developed a petal tissue bioassay to evaluate 172 bacterial isolates for the control of $B$. cinerea, which allowed for more rapid screening of the collection. However, in vitro assays are not always an option for investigating plant-microbe interactions. When selecting bacteria for the biocontrol of Pseudomonas syringae pv. tomato from a collection of approximately 70 strains, greenhouse trials were used as an alternative to an in vitro study to identify a few strains for field testing. Two strains were identified for their ability to reduce disease through this selection process (Wilson et al. 2002). In our study, most of the top-performing bacteria would have been overlooked if the dual-culture assay was the sole means of selecting strains for greenhouse validation. A dual-culture assay can lead to a narrow view of potential biocontrol candidates because it focuses on one or few modes of action. A screening assay that considers the complexity of the system, including the pathogen, antagonist,

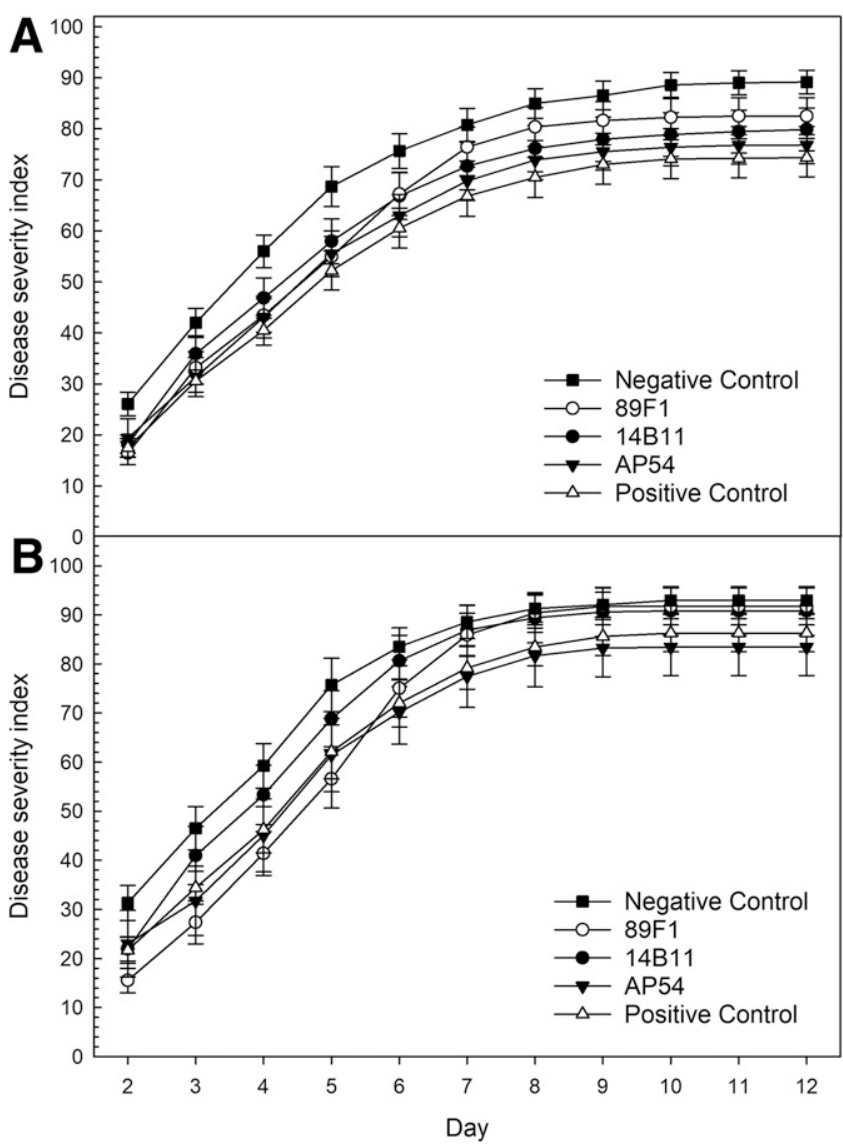

Fig. 8. Disease severity index across all rating days of the three top-performing strains from the greenhouse validation trial. The disease severity index was calculated using the daily ratings of individual flowers. Plants were rated daily for 11 days for both time replicates in $\mathbf{A}$, experiment 1 and $\mathbf{B}$, experiment 2. The negative control (no bacteria) is represented with the black squares, and the positive control (Bacillus subtilis QST 713) is represented by the white triangles. Each treatment was replicated 12 times. The error bars denote standard error. plant, and environment, is needed to capture potential biocontrol candidates (Köhl et al. 2019). An augmented design was used in our study to screen the entire bacterial collection in the initial greenhouse trial and select top strains for further evaluation. This type of experimental design is used in plant breeding programs to allow for low replication of varieties, whereas the checks or controls are overreplicated (Federer and Raghavarao 1975).

Seven strains selected from the initial greenhouse trial were evaluated in the validation trial to confirm the ability of these strains to reduce gray mold severity in petunia. Although all seven strains performed better than the negative control, three strains were identified as the top performers based on AUDPC and disease severity index. Pseudomonas protegens AP54 and Pseudomonas chlororaphis 14B11 were top performers in AUDPC and across all rating days for disease severity index, whereas Pseudomonas fluorescens 89F1 was a top performer when looking at reduced disease severity index. These three top strains were from the genus Pseudomonas. Pseudomonas spp. have shown potential for biocontrol of $B$. cinerea infection in various crops. Several Pseudomonas fluorescens strains were identified based on their ability to reduce disease severity caused by $B$. cinerea in greenhouse-grown tomato plants, with some of the strains capable of reducing disease when used in combination with fungicides (Yildiz et al. 2007). Pseudomonas sp. PsJN isolated from onion root was used to successfully reduce $B$. cinerea infection in grapevine plantlets (Barka et al. 2002), and a Pseudomonas fluorescens strain, originally isolated from petunia leaves and flowers, reduced $B$. cinerea infection on petunia flowers (Gould et al. 1996).

Conclusion. The greenhouse trials and rating methods that focused on flower disease severity were successful in identifying potential biocontrol agents for gray mold in petunia. These selected beneficial bacterial strains have the potential to be formulated into biocontrol products for the ornamental greenhouse industry. Biocontrol products added into an integrated pest management plan can help the ornamental greenhouse industry move toward a more sustainable production system. Future studies will need to identify the modes of action for disease control so that the bacteria can be utilized in the most effective way. Understanding more about the mode of action will also provide information for the best method to formulate and implement these selected bacteria for the control of $B$. cinerea in greenhouse floriculture production.

\section{Acknowledgments}

We thank Laura Chapin for technical assistance, Dr. David Francis and Bo Luan for statistical advice, and Dr. Christopher G. Taylor and Dr. Joseph W. Kloepper for providing the bacterial strains.

\section{Literature Cited}

Aly, H. 2009. Role of Pseudomonas produced hydrogen cyanide in biological control of plant-parasitic nematodes. Dissertation. University of Missouri-St. Louis, St. Louis, MO

Barka, E. A., Gognies, S., Nowak, J., Audran, J. C., and Belarbi, A. 2002. Inhibitory effect of endophyte bacteria on Botrytis cinerea and its influence to promote the grapevine growth. Biol. Control 24:135-142.

Bates, D., Maechler, M., Bolker, B., and Walker, S. 2015. Fitting linear mixed effects models using lme4. J. Stat. Softw. 67:1-48.

Chand, T., and Logan, C. 1984. Antagonists and parasites of Rhizoctonia solani and their efficacy in reucing stem canker of potato under controlled conditions. Trans. Br. Mycol. Soc. 83:107-112.

Cook, R., and Baker, K. 1983. The Nature and Practice of Biological Control of Plants Pathogens. The American Phytopathological Society, St. Paul, MN.

Cosseboom, S. D., Ivors, K. L., Schnabel, G., Bryson, P. K., and Holmes, G. J. 2019. Within-season shift in fungicide resistance profiles of Botrytis cinerea in California strawberry fields. Plant Dis. 103:59-64.

Dean, R., Van Kan, J. A. L., Pretorius, Z. A., Hammond-Kosack, K. E., Di Pietro, A., Spanu, P. D., Rudd, J. J., Dickman, M., Kahmann, R., Ellis, J., and Foster, G. D. 2012. The top 10 fungal pathogens in molecular plant pathology. Mol. Plant Pathol. 13:414-430.

Dik, A. J., and Wubben, J. P. 2007. Epidemiology of Botrytis cinerea diseases in greenhouses. Pages 319-333 in: Botrytis: Biology, Pathology and Control. Y. Elad, B. Williamson, P. Tudzynski, and N. Delen, eds. Springer, Dordrecht, The Netherlands.

Elad, Y., and Steward, A. 2007. Microbial control of Botrytis spp. Pages 223-241 in: Botrytis: Biology, Pathology and Control. Y. Elad, B. Williamson, P. Tudzynski, and N. Delen, eds. Springer, Dordrecht, The Netherlands. 
Federer, W. T., and Raghavarao, D. 1975. On augmented designs. Biometrics 31:29-33.

Fokkema, N. J. 1973. The rôle of saprophytic fungi in antagonism against Drechslera sorokiniana (Helminthosporium sativum) on agar plates and on rye leaves with pollen. Physiol. Plant Pathol. 3:195-205.

Fravel, D. R. 2005. Commercialization and implementation of biocontrol. Annu. Rev. Phytopathol. 43:337-359.

Fungicide Resistance Action Committee. 2018. FRAC list of plant pathogenic organisms resistant to disease control agents. https://www.frac.info/docs/ default-source/publications/list-of-resistant-plant-pathogens/list-of-resistantplant-pathogenic-organisms_may-2018.pdf?sfvrsn=a2454b9a_2

Gould, A. B., Kobayashi, D. Y., and Bergen, M. S. 1996. Identification of bacteria for biological control of Botrytis cinerea on petunia using a petal disk assay. Plant Dis. 80:1029-1033.

Horiuchi, S., and Hori, M. 1980. A simple greenhouse technique for obtaining high levels of clubroot incidence. Bull. Chugoku Natl. Agric. Exp. Stn. Ser. E. 17:33-35.

Kefi, A., Ben Slimene, I., Karkouch, I., Rihouey, C., Azaeiz, S., Bejaoui, M., Belaid, R., Cosette, P., Jouenne, T., and Limam, F. 2015. Characterization of endophytic Bacillus strains from tomato plants (Lycopersicon esculentum) displaying antifungal activity against Botrytis cinerea Pers. World J. Microbiol. Biotechnol. 31:1967-1976.

Kerr, J. R. 1999. Bacterial inhibition of fungal growth and pathogenicity. Microb. Ecol. Health Dis. 11:129-142.

Köhl, J., Kolnaar, R., and Ravensberg, W. 2019. Mode of action of microbial biological control agents against plant diseases: Relevance beyond efficacy. Front. Plant Sci. 10:845.

Lamichhane, J., Dachbrodt-Saaydeh, S., Kudsk, P., and Messean, A. 2016. Toward a reduced reliance on conventional pesticides in European agriculture. Plant Dis. 100:10-24

McSpadden Gardener, B. B., Gutierrez, L. J., Joshi, R., Edema, R., and Lutton, E. 2005. Distribution and biocontrol potential of phlD+ Pseudomonads in corn and soybean fields. Phytopathology 95:715-724.

Meister Media Worldwide, ed. 2014. Special Report: Biopesticides Primed for Growth. http://phyllombioproducts.com/documents/MeisterMedia\%20Worldwide's \%20Report\%20\%202014_Biopesticides\%20-\%20Primed\%20for\%20Growth.pdf

Milus, E. A., and Rothrock, C. S. 1997. Efficacy of bacterial seed treatments for controlling Pythium root rot of winter wheat. Plant Dis. 81:180-184.

Muñoz, M., Faust, J. E., and Schnabel, G. 2019. Characterization of Botrytis cinerea from commercial cut flower roses. Plant Dis. 103:1577-1583.

Pal, K. K., and McSpadden Gardener, B. B. 2006. Biological control of plant pathogens. Online publication. Plant Health Instr. doi: 10.1094/PHI-A-20061117-02.

Paulitz, T. C., and Bélanger, R. R. 2001. Biological control in greenhouse systems. Annu. Rev. Phytopathol. 39:103-133.
R Core Team. 2019. R: A Language and Environment for Statistical Computing. https://www.r-project.org/

Redmond, J. C., Marois, J. J., and MacDonald, J. D. 1987. Biological control of Botrytis cinerea on Roses with epiphytic microorganisms. Plant Dis. 71: 799-802.

Rigotti, S., Gindro, K., Richter, H., and Viret, O. 2002. Characterization of molecular markers for specific and sensitive detection of Botrytis cinerea Pers.: Fr. in strawberry (Fragariaxananassa Duch.) using PCR. FEMS Microbiol. Lett. 209:169-174.

Royse, D. J., and Ries, S. M. 1978. The influence of fungi isolated from peach twigs on the pathogenicity of Cytospora cincta. Ecol. Epidemiol. 68:603-607.

Shaner, G., and Finney, R. E. 1977. The effect of nitrogen fertilization on the expression of slow-mildewing resistance in knox wheat. Phytopathology 67 1051-1056.

Strelkov, S. E., Tewari, J. P., and Smith-Degenhardt, E. 2006. Characterization of Plasmodiophora brassicae populations from Alberta, Canada. Can. J. Plant Pathol. 28:467-474.

Subedi, N., Taylor, C. G., Paul, P. A., and Miller, S. A. 2019. Combining partial host resistance with bacterial biocontrol agents improves outcomes for tomatoes infected with Ralstonia pseudosolanacearum. Crop Prot., in press. doi.org/10.1016/j.cropro.2019.03.024

Syed Ab Rahman, S. F., Singh, E., Pieterse, C. M. J., and Schenk, P. M. 2018. Emerging microbial biocontrol strategies for plant pathogens. Plant Sci. 267: 102-111.

Trotel-Aziz, P., Couderchet, M., Biagianti, S., and Aziz, A. 2008. Characterization of new bacterial biocontrol agents Acinetobacter, Bacillus, Pantoea and Pseudomonas spp. mediating grapevine resistance against Botrytis cinerea. Environ. Exp. Bot. 64:21-32

Wang, S., Hu, T., Jiao, Y., Wei, J., and Cao, K. 2009. Isolation and characterization of Bacillus subtilis EB-28, an endophytic bacterium strain displaying biocontrol activity against Botrytis cinerea Pers. Front. Agric. China 3:247-252.

Whipps, J. M. 1987. Effect of media on growth and interactions between a range of soil-borne glasshouse pathogens and antagonistic fungi. New Phytol. 107:127-142.

Wilson, M., Campbell, H. L., Ji, P., Jones, J. B., and Cuppels, D. A. 2002. Biological control of bacterial speck of tomato under field conditions at several locations in North America. Phytopathology 92:1284-1292.

Xia, Y., Deng, X., Zhou, P., Shima, K., and Teixeira de Silva, J. 2006. The world floriculture industry: Dynamics of production and markets. Pages 336-347 in: Floriculture, Ornamental and Plant Biotechnology. J. A. Teixeira da Silva, ed. Global Science Books, Middlesex, United Kingdom.

Yildiz, F., Yildiz, M., Delen, N., Coşkuntuna, A., Kinay, P., and Türküsay, H. 2007. The effects of biological and chemical treatment on gray mold disease in tomatoes grown under greenhouse conditions. Turk. J. Agric. For. 31:319-325. 